\title{
Serum Lipid Concentrations and Growth Characteristics in 12-year-old Children Born Small for Gestational Age
}

\author{
SIRPA TENHOLA, ANNELI MARTIKAINEN, EERO RAHIALA, EILA HERRGÅRD, PIRJO \\ HALONEN, AND RAIMO VOUTILAINEN
}

Department of Pediatrics, Kuopio University Hospital [S.T., A.M., E.R., E.H, R.V.], and Computing

Centre, Kuopio University [P.H.], FIN-70211 Kuopio, Finland.

\begin{abstract}
According to Barker's hypothesis, children born small for gestational age (SGA) are at increased risk for cardiovascular diseases in adulthood. The aim of our study was to determine whether retarded fetal growth is associated with dyslipidemia in childhood and, if so, to find predictive factors in the growth characteristics of SGA children. We studied the serum lipid concentrations of 55 SGA children and their 55 appropriate for gestational age control subjects at the age of $12 \mathrm{y}$. Growth variables were recorded at birth, $5 \mathrm{y}$, and $12 \mathrm{y}$ of age. The study group consisted of all full-term SGA children born at our university hospital during a 22-mo period in 1984-1986. Nearly half of the SGA children (47.3\%) were in the highest quartile for serum total cholesterol of the appropriate for gestational age children $(p=0.038)$. In multiple logistic regression analysis, poor catch-up growth in height (odds ratio, 13.8; 95\% confidence interval, 2.0-97.5), female sex (odds ratio, 8.1; 95\% confidence interval, 1.3-48.9), and early stage of puberty (odds ratio, 7.5; $95 \%$ confidence interval, 1.2-46.5) predicted high cholesterol level in the SGA children. By the age of $5 \mathrm{y}, 20$ (36.4\%) SGA
\end{abstract}

\section{ABSTRACT}

children showed catch-up growth of $\geq 2$ SD scores in height, and $21(38.2 \%)$ SGA children showed catch-up growth of $\geq 2$ SD scores in weight from birth. At the age of $12 \mathrm{y}$, the SGA children were still significantly shorter $(p<0.001)$ and lighter $(p<0.05)$ than the appropriate for gestational age children, even though their pubertal development was similarly advanced. In conclusion, to be born SGA has long-term consequences for later growth and may already influence the level of serum total cholesterol before the teens. SGA children with poor catch-up growth in height may be at the highest risk for hypercholesterolemia. (Pediatr Res 48: 623-628, 2000)
SGA, small for gestational age
Abbreviations
AGA, appropriate for gestational age
TC, total cholesterol
PSEH, parent-specific expected height
TG, triglycerides

Serum lipids and lipoproteins are important determinants for the development of atherosclerosis and coronary heart disease. Previous studies have revealed that antemortem serum lipid values in children and young adults correlate significantly with atherosclerotic changes $(1,2)$. In addition, follow-up studies of children have shown that concentrations of serum total cholesterol tend to track for several years, and measurements obtained in childhood predict total and LDL cholesterol levels in adults (3-5).

Findings by Barker et al. (6-9) have led to the "fetal origins" hypothesis, which suggests that hypertension, hyperlipidemia, and non-insulin-dependent diabetes are programmed by malnutrition in utero. Low growth rate during

Received November 9, 1999; accepted June 14, 2000.

Correspondence and reprint requests: Sirpa Tenhola, M.D., Department of Pediatrics, Kuopio University Hospital, P.O. Box 1777, FIN-70211 Kuopio, Finland.

Supported by Pediatric Research Foundation, Kuopio University Hospital, and Academy of Finland. fetal life and infancy is associated with increased rates of death caused by cardiovascular diseases in adulthood (10-12). This association is seen in individuals born SGA rather than in those born prematurely (10). Moreover, Barker et al. (13) have reported a relationship between small abdominal circumference at birth and increased serum concentrations of total and LDL cholesterol and apolipoprotein B in adulthood. However, there have been few reports on the relationship between low birth weight or retarded fetal growth and serum lipid concentrations in childhood (14-16).

Previous growth studies have indicated that children born SGA have many times higher risk of being short adults $(<-2$ SD score) than those born at normal size. Furthermore, $8 \%$ of children born SGA are still $<-2$ SD score at final height (17-19). According to recent reports, birth length, i.e. the magnitude of fetal growth retardation, and target height, i.e. genetic influence, are the important predictors for catch-up growth and final height in children born $\operatorname{SGA}(19,20)$. 
The aim of our study was to determine whether retarded fetal growth leads to dyslipidemia already in childhood, and if so, to find predictive factors in the growth pattern of SGA children. The hypothesis was tested in a case-control setting in 12-y-old SGA children and their sex- and age-matched AGA control subjects in eastern Finland, where the prevalence of coronary heart disease has been exceptionally high (21).

\section{METHODS}

\section{Definitions}

$S G A$ was defined as birth weight and/or length and/or ponderal index $>2$ SD score below the respective mean for the gestational age (22). The ponderal index was calculated as [weight $(\mathrm{g}) /$ length $\left.{ }^{3}(\mathrm{~cm})\right] \times 100 . A G A$ was defined as birth weight, birth length, and ponderal index $\geq-2$ SD score and $\leq$ $+2 \mathrm{SD}$ score of the respective mean for the gestational age. Full-term was applied to babies born at or after wk 37 and before the 42nd wk of gestation (calculated from the beginning of the last menstruation). The gestational age of SGA babies was confirmed by the method of Dubowitz et al. (23) during the first $3 \mathrm{~d}$ after birth. If there was a discrepancy of $2 \mathrm{wk}$ or more between the estimations, the Dubowitz assessment was selected. According to the prevailing recommendation by the Finnish Pediatric Society (24), hypercholesterolemia was defined as serum TC $\geq 5.5 \mathrm{mM}$, or as LDL cholesterol $\geq 4.0$ $\mathrm{mM}$. PSEH was calculated as determined by Pere et al. (25), and body mass index according to the formula weight $(\mathrm{kg}) /$ height ${ }^{2}(\mathrm{~m})$. Good catch-up growth was defined as growth that increased $\geq 2$ SD score, and poor catch-up growth was defined as growth that increased $<2 \mathrm{SD}$ score, in height or in weight from birth by the age of $5 \mathrm{y}$.

\section{Subjects}

All children included in the present study were originally recruited in a prospective follow-up study evaluating the outcome of babies born to hypertensive mothers and that of preterm babies $(26,27)$. The children were born at Kuopio University Hospital during the 22-mo period between April 1, 1984, and March 31, 1986 (excluding July in 1984 and 1985). During this period, there were 3790 live births. The follow-up study population comprised 621 children including all fullterm babies who were born SGA during this period. All 73 nonmalformed full-term SGA children (70 singletons and three twins) were included in the present study. Of the SGA group, five children could not be reached, one child was excluded because of a metabolic disease (Salla's disease), one child was excluded by age (12.8 y), and 11 were unwilling to participate in the study (Fig. 1). Thus, 18 (24.7\%) subjects of the original SGA children were excluded from the study. The majority of the SGA children who refused were unwilling to participate because of a fear of giving a blood sample, even though a topical local anesthetic cream (Emla, Astra, Södertälje, Sweden) could have been used. Each SGA child had as the control subject the next born full-term AGA child matched for sex. At the age of $12 \mathrm{y}, 55$ SGA children ( 20 boys and 35 girls) and 55 AGA control subjects participated in this study. The mean age

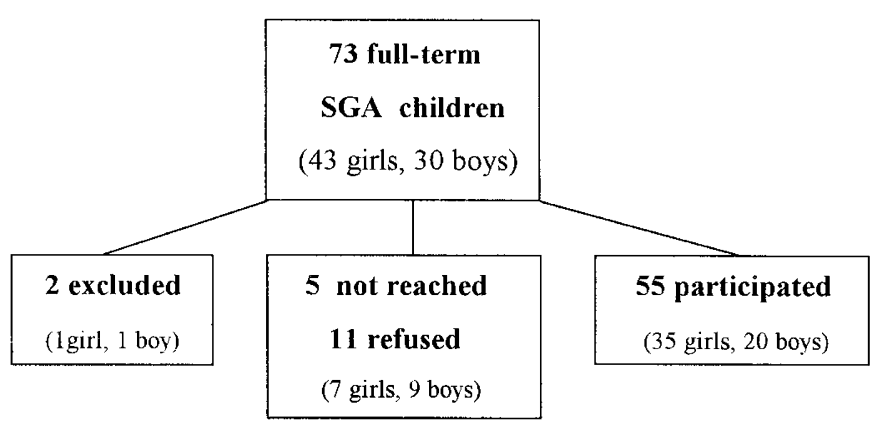

Figure 1. Formation of the group of 55 participating SGA children.

( \pm SD) in both the study and the control group was $12.2 \pm$ $0.2 \mathrm{y}$. The study protocol was approved by the Research Ethics Committee of Kuopio University Hospital. Informed written consent was obtained from the child and the parents.

\section{Procedures}

Perinatal data. Perinatal data, e.g. birth weight, length, head circumference, and duration of gestation, had previously been obtained from hospital records. Birth weight, length, and head circumference had been measured in the delivery room immediately after birth. The birth measures were converted into SD score by plotting them on the growth charts and adjusting the birth measures for duration of gestation and sex (22). The mean ( \pm SD) gestational age was $39.0 \pm 1.4 \mathrm{wk}$ in the SGA group and $39.7 \pm 1.5 \mathrm{wk}$ in the AGA group $(p=0.007)$. The perinatal characteristics of the SGA and AGA groups are shown in Table 1. The mean birth measures of those who had dropped out of the study did not differ from those of the participating SGA children. Of the 55 SGA children studied, retarded intrauterine growth was classified as asymmetrical (birth weight or birth length or ponderal index $<-2$ SD score) in 25 cases and symmetrical (birth weight and birth length $<$ -2 SD score) in 30 cases.

Anthropometric measures and pubertal development. At the ages of 5 and $12 \mathrm{y}$, height was measured with a calibrated Harpenden stadiometer and recorded to the nearest $0.1 \mathrm{~cm}$, and weight was recorded to the nearest $0.1 \mathrm{~kg}$. Height was converted to SD score and weight to percentages in relation to the mean weight for height by using the current Finnish reference values for height and relative weight (Pegasos V 3.9.2, Pediatric Research Foundation, Helsinki, Finland). Weight at the age of $5 \mathrm{y}$ was also converted to SD score by using the data from the official national growth-chart material. Head circumference was measured with a metal measuring tape as the maximum circumference between the supraorbital ridge and the occiput. A complete physical examination was performed for all children by one of the authors (S.T. or E.R.). Thicknesses of the subscapular and triceps skin-folds were measured three times with a Harpenden skin-fold caliper and recorded to the nearest $0.2 \mathrm{~mm}$. The mean value was used in the analysis. Pubertal stage was defined according to the Tanner scale (28, 29). Pubertal stages were further classified into two classes according to the Tanner scores by counting pubic hair and breast scores for girls and pubic hair and genital scores for boys (prepuberty or early stage of puberty; scores of $\leq 4$, late stage 
Table 1. Perinatal anthropometric characteristics and parental heights of children born SGA and AGA.

\begin{tabular}{|c|c|c|c|c|}
\hline \multirow{2}{*}{$\begin{array}{c}\text { Characteristic } \\
\text { Birth weight (SDscore) }\end{array}$} & \multicolumn{2}{|c|}{ SGA $(n=55)$} & \multicolumn{2}{|c|}{$\operatorname{AGA}(n=55)$} \\
\hline & $-2.44 \dagger$ & $(-2.58,-2.30)$ & -0.24 & $(-0.51,0.03)$ \\
\hline Birth weight (g) & $2452 \dagger$ & $(2367,2537)$ & 3455 & $(3326,3584)$ \\
\hline Girls & $2389 \dagger$ & $(2282,2496)$ & 3395 & $(3229,3561)$ \\
\hline Birth length (SDscore) & $-2.27 \dagger$ & $(-2.53,-2.01)$ & -0.08 & $(-0.40,0.24)$ \\
\hline Birth length (cm) & $46.2 \dagger$ & $(45.6,46.8)$ & 50.4 & $(49.8,51.0)$ \\
\hline Girls & $45.8 \dagger$ & $(45.2,46.4)$ & 50.0 & $(49.2,50.8)$ \\
\hline Head circumference $(\mathrm{cm})$ & $32.6 \dagger$ & $(32.3,33.0)$ & 34.6 & $(34.2,35.0)$ \\
\hline Girls & $32.5 \dagger$ & $(32.1,32.9)$ & 34.3 & $(33.8,34.8)$ \\
\hline Boys & $32.9 \dagger$ & $(32.2,33.6)$ & 35.1 & $(34.4,35.8)$ \\
\hline Ponderal index $\left(\mathrm{g} / \mathrm{cm}^{3}\right)$ & $2.49 \dagger$ & $(2.42,2.56)$ & 2.69 & $(2.64,2.74)$ \\
\hline Girls & $2.48 \dagger$ & $(2.40,2.56)$ & 2.71 & $(2.64,2.78)$ \\
\hline
\end{tabular}

Values are shown as the mean ( $95 \%$ confidence intervals).

$* p<0.01, \dagger p<0.001$, SGA vs AGA, Wilcoxon matched-pairs signed rank test for differences.

of puberty; scores of $\geq 5$ ). Information on parental heights was obtained by a questionnaire, with the exception of missing data for one mother and six fathers.

Socioeconomic classification. Socioeconomic class was determined on the basis of parental occupation and was coded using the scale presented by the Central Statistical Office of Finland in 1989 (30). Six occupational classes were used in the study (Table 2). The higher occupation of the parents was used as the socioeconomic status of the household. Social classes were further classified into two classes: high (I-IV) and low (V-VI). No statistical difference was found in social classes between the SGA and AGA groups ( $p=0.134$ ).

Laboratory methods. After an overnight fast, blood samples were taken from the antecubital vein with the subject lying recumbent. Serum TC and HDL cholesterol were measured enzymatically by an automatic photometric method (Boehringer Mannheim, Mannheim, Germany). For TC, the interassay coefficient of variation was $3.1 \%$ at $4.0 \mathrm{mM}$, whereas for HDL cholesterol the interassay coefficient of variation was $4.1 \%$ at $0.84 \mathrm{mM}$ and $3.8 \%$ at $1.69 \mathrm{mM}$. Serum TG were analyzed enzymatically (Boehringer Mannheim), and the interassay coefficient of variation was $1.6 \%$ at $2.45 \mathrm{mM}$ and $3.2 \%$ at 1.23 $\mathrm{mM}$. LDL cholesterol concentrations were calculated by the Friedewald-Fredrickson formula [LDL cholesterol $=\mathrm{TC}-$ (HDL cholesterol + TG/2.2)] (31).

Table 2. Socioeconomic classification of families in $S G A$ and $A G A$ groups

\begin{tabular}{llcc}
\hline & Socioeconomic class & $\begin{array}{c}\text { SGA } \\
(n=55)\end{array}$ & $\begin{array}{c}\text { AGA } \\
(n=55)\end{array}$ \\
\hline I & Farmers & 7 & 4 \\
II & Employers & 8 & 9 \\
III & Upper-level employees & 6 & 10 \\
IV & Lower-level employees & 16 & 21 \\
V & Manual workers & 18 & 11 \\
VI & Others & 0 & 0 \\
\hline
\end{tabular}

Data analysis. Data were analyzed using the SPSS for Windows statistical package (version 7.5, SPSS Inc., Chicago, IL, U.S.A.). All continuous variables were examined for normality with the Kolmogorov-Smirnov test. Because the data were based on matched pairs (SGA children versus AGA children) and some of the variables were distributed nonnormally, Wilcoxon matched-pairs signed rank test was used to compare the means. The Mann-Whitney test was used when the lipid variables of SGA girls and SGA boys were compared. The McNemar test was used to compare the dichotomous variables of the SGA and AGA children. Because some variables were distributed nonnormally, confidence intervals were calculated using a critical value from the $t$ distribution. A significance level of $p<0.05$ was used for all analyses. In the multiple logistic regression analysis, the TC variable was dichotomized in the group of the SGA children; as the cut-off point, we used the TC level of the 75th percentile of the AGA control subjects. The variables included in the multiple logistic regression analysis were sex, pubertal stage, catch-up growth in height and in weight, and social class. Pubertal stages and social classes were recoded into two classes as described earlier.

\section{RESULTS}

Growth characteristics at the age of $5 y$. During this evaluation the mean $( \pm \mathrm{SD})$ age of the children was $5.0 \pm$ $0.1 \mathrm{y}$ in both the study and the control groups. At the age of $5 \mathrm{y}$, the SGA children were significantly shorter and lighter, expressed in SD score, than the AGA children $(p<0.001)$, and their body mass index was also lower than that of the AGA children $(p=0.001)$. Twenty $(36.4 \%)$ SGA children had experienced $\geq 2$ SD score catch-up growth in height, and 21 (38.2\%) SGA children had caught-up $\geq 2$ SD score in weight from birth to the age of $5 \mathrm{y}$. Four (7.3\%) SGA children remained short $(<-2 \mathrm{SD}$ score $)$ at $5 \mathrm{y}$ of age. 
Anthropometric measures at the age of $12 y$. At $12 \mathrm{y}$ of age, the SGA children were still significantly shorter and lighter and had smaller head circumference than the AGA children, even when boys and girls were analyzed separately. The SGA children were also thinner in terms of body mass index and subscapular and triceps skin-folds (Table 3). In addition, the mothers of the SGA children were significantly shorter than those of the AGA children (Table 1). Thus, PSEH was lower in the SGA children than in the AGA children (Table 3).

Pubertal development. Pubertal development did not differ between the SGA and the AGA children $(p=0.819)$. In the former group, $26(47.3 \%)$ children and, in the latter, 25 $(45.5 \%)$ children were prepubertal or in early puberty (as defined in the "Methods"). Of those SGA children who were prepubertal or in early puberty, $10(28.6 \%)$ were girls and 16 $(80.0 \%)$ were boys. In the AGA children, the numbers were eight (22.9\%) and 17 (85.0\%), respectively. In both the SGA and AGA groups, nine of the girls $(25.7 \%)$ had menstruated.

Serum lipid concentrations. Twenty-six (47.3\%) SGA children had their serum TC concentration and 25 (45.5\%) their LDL cholesterol concentration in the highest quartile of that of the control group (Table 4). However, mean serum TC, LDL, HDL cholesterol, or TG concentrations did not differ significantly between the SGA and AGA children (Table 5). When boys and girls were analyzed separately, the SGA girls had significantly higher mean TC concentration than the AGA girls did $(p=0.024)$. The SGA girls also had significantly higher mean TC concentration than the SGA boys $(p=0.047)$. Hypercholesterolemia was confirmed in eight (14.5\%) SGA and five $(9.1 \%)$ AGA children. Of these hypercholesterolemic children, four SGA children and one AGA child also had high concentration of LDL cholesterol.
Table 4. Numbers and percentages of SGA children having level of $T C, L D L$ cholesterol, and $T G$ in highest quartile of that of $A G A$ group and level of HDL cholesterol in lowest quartile of that of AGA group

\begin{tabular}{lcc}
\hline $\begin{array}{l}\text { Limits of highest } \\
\text { quartiles for TC, }\end{array}$ & & \\
LDL, and TG and & & \\
lowest quartile for & SGA group & \\
HDL in AGA group & $n(\%)$ & 0 value* \\
\hline TC $\geq 4.8 \mathrm{mM}$ & $26(47.3)$ & 0.038 \\
LDL $\geq 2.92 \mathrm{mM}$ & $25(45.5)$ & 0.072 \\
TG $\geq 1.13 \mathrm{mM}$ & $15(27.3)$ & 1.000 \\
HDL $\leq 1.08 \mathrm{mM}$ & $13(23.6)$ & 1.000 \\
\hline
\end{tabular}

* SGA vs AGA, McNemar test for differences.

Table 5. Serum concentrations of TC, LDL cholesterol, HDL cholesterol, and TG in children born SGA and AGA at $12 y$

\begin{tabular}{lccccc}
\hline \multicolumn{1}{c}{ Lipid } & \multicolumn{2}{c}{ SGA $(n=55)$} & \multicolumn{2}{c}{ AGA $(n=55)$} & $p$ value* \\
\hline TC $(\mathrm{mM})$ & 4.58 & $(4.34,4.84)$ & 4.33 & $(4.13,4.53)$ & 0.111 \\
LDL $(\mathrm{mM})$ & 2.85 & $(2.66,3.04)$ & 2.62 & $(2.44,2.80)$ & 0.113 \\
HDL $(\mathrm{mM})$ & 1.30 & $(1.22,1.38)$ & 1.27 & $(1.19,1.35)$ & 0.952 \\
TG $(\mathrm{mM})$ & 0.93 & $(0.82,1.04)$ & 0.94 & $(0.81,1.07)$ & 0.842 \\
\hline
\end{tabular}

Values are shown as the mean (95\% confidence intervals).

* Wilcoxon matched-pairs signed rank test for differences

Factors associated with high TC levels in the SGA children. Female sex, poor catch-up growth in height by $5 \mathrm{y}$ of age, and pre- or early pubertal stage at $12 \mathrm{y}$ of age were associated with high TC level in the SGA children (Table 6). All the factors included in the multiple logistic regression analysis are shown in Table 6 . Female sex increased by 8.1 -fold the risk of an SGA child having a TC concentration $\geq 4.8 \mathrm{mM}$. Pre- or early pubertal stage at 12 y of age increased by 7.5 -fold the risk of high TC level. The SGA children with poor catch-up growth

Table 3. Anthropometric data and PSEH of children born SGA and AGA at $12 y$

\begin{tabular}{|c|c|c|c|c|}
\hline \multirow{2}{*}{$\begin{array}{l}\text { Characteristic } \\
\text { Height (SDscore) }\end{array}$} & \multicolumn{2}{|c|}{ SGA $(n=55)$} & \multicolumn{2}{|c|}{$\operatorname{AGA}(n=55)$} \\
\hline & $-0.16 \div$ & $(-0.40,0.08)$ & 0.60 & $(0.33,0.87)$ \\
\hline Height (cm) & $150.1 \dagger$ & $(148.3,151.9)$ & 155.8 & $(153.8,157.8)$ \\
\hline Girls & $151.2 \dagger$ & $(149.2,153.2)$ & 156.4 & $(153.5,159.3)$ \\
\hline PSEH (SDscore) & $\begin{array}{c}-\mathbf{0 . 2 0} \\
(n=51)\end{array}$ & $(-0.34,-0.06)$ & $\begin{array}{c}\mathbf{0 . 0 8} \\
(n=53)\end{array}$ & $(-0.09,0.25)$ \\
\hline Head circumference (SDscore) & $-1.02 \ddagger$ & $(-1.31,-0.73)$ & -0.02 & $(-0.32,0.28)$ \\
\hline Boys & $52.8 \dagger$ & $(52.0,53.6)$ & 54.8 & $(54.0,55.6)$ \\
\hline Weight (\%) & $-1 *$ & $(-6,4)$ & 9 & $(3,15)$ \\
\hline Weight (kg) & $39.7+$ & $(37.6,41.8)$ & 48.6 & $(45.0,52.2)$ \\
\hline Girls & $39.7 \dagger$ & $(37.3,42.1)$ & 48.6 & $(44.0,53.2)$ \\
\hline Boys & $39.5^{*}$ & $(35.4,43.6)$ & 48.6 & $(42.5,54.7)$ \\
\hline Body mass index $\left(\mathrm{kg} / \mathrm{m}^{2}\right)$ & $17.5 \dagger$ & $(16.7,18.3)$ & 19.8 & $(18.7,20.9)$ \\
\hline Boys & 10.4 & $(6.7,14.1)$ & 15.3 & $(9.7,20.9)$ \\
\hline Triceps skin-fold (mm) & $14.7 *$ & $(12.9,16.5)$ & 18.3 & $(15.7,20.9)$ \\
\hline Girls & 14.8 & $(12.5,17.1)$ & 18.2 & $(14.8,21.6)$ \\
\hline Boys & 14.4 & $(11.0,17.8)$ & 18.4 & $(13.8,23.0)$ \\
\hline
\end{tabular}

Values are shown as the mean (95\% confidence intervals).

$* p<0.05, \dagger p<0.01, \ddagger p<0.001$, SGA vs. AGA, Wilcoxon matched-pairs signed rank test for differences 
Table 6. Factors predicting high TC level in SGA children

\begin{tabular}{|c|c|c|c|c|}
\hline Factor & $\begin{array}{r}\text { Regression } \\
\text { coefficient }\end{array}$ & Significance & $\begin{array}{l}\text { Odds } \\
\text { ratio }\end{array}$ & $\begin{array}{c}\text { Confidence } \\
\text { interval } \\
(95 \%)\end{array}$ \\
\hline Female sex & 2.1 & 0.023 & 8.1 & $1.3,48.9$ \\
\hline $\begin{array}{l}\text { Prepuberty or early } \\
\text { pubertal stage }\end{array}$ & 2.0 & 0.031 & 7.5 & $1.2,46.5$ \\
\hline $\begin{array}{c}\text { Poor catch-up growth in } \\
\text { height }(<2 \text { SD score) }\end{array}$ & 2.6 & 0.009 & 13.8 & $2.0,97.5$ \\
\hline $\begin{array}{l}\text { Poor catch-up growth in } \\
\text { weight }(<2 \text { SD score) }\end{array}$ & -1.2 & 0.209 & 0.3 & $0.1,1.9$ \\
\hline Low social class & 0.4 & 0.551 & 1.5 & $0.4,6.0$ \\
\hline
\end{tabular}

in height were at a 13.8-fold risk of having high level of TC. In this multiple logistic regression model, catch-up growth in weight or social class did not affect the risk of an SGA child having high TC level. The results of the logistic regression analysis did not change, even though catch-up growth in height and in weight were covariates that were analyzed separately in the model. The results did not change even when maternal height and gestational age were used as covariates in the analysis.

\section{DISCUSSION}

The present study revealed that the high levels of TC, which exceeded the limit of the 75th percentile of the AGA children, were significantly more common in the SGA children at the age of $12 \mathrm{y}$. However, the mean concentrations of serum lipids did not differ between the two groups. In multiple logistic regression analysis, the factors that predicted high TC level in the SGA children were poor catch-up growth in height, female sex, and pre- or early pubertal stage at the age of $12 \mathrm{y}$. The SGA children were leaner and shorter than the AGA children at both 5 and $12 \mathrm{y}$ of age, even though their pubertal development was the same as that of the control subjects.

We were able to study $75.3 \%$ of the original SGA subjects, which is a relatively good percentage $12 \mathrm{y}$ after birth. The advantage of the present study is the case-control setting, in which the SGA children were carefully matched by age and their pubertal development advanced similarly to that of their control subjects. The term $S G A$ has no generally accepted standard definition. The definition of SGA can be based on birth weight, height, or both, and the cut-off limits for defining SGA can be -2 SD score, or the 3rd, 5th, or 10th percentile for gestational age $(18,19)$. SGA has more often been defined in terms of birth weight than in terms of birth length. In the present study, we accepted four definitions: weight $(n=20)$, length $(n=4)$, weight and length $(n=30)$, or ponderal index $(n=1)>2$ SD score below the mean for the gestational age. The discrepancy in the definitions of SGA causes differences in the study populations in SGA studies.

At the age of $5 \mathrm{y}, 7.3 \%$ of our SGA children remained short $(<-2$ SD score). Albertsson-Wikland et al. (32) showed that $5 \%$ of girls and $11 \%$ of boys born SGA had height $<-2$ SD score at $4 \mathrm{y}$ of age, which is quite similar to our finding at $5 \mathrm{y}$. According to recent reports, target height is known to be an important predictor for catch-up growth and final height in SGA children $(19,20)$. However, PSEH of our SGA children was slightly lower than that of the control subjects owing to the shortness of the mothers of the SGA children. Thus, it is possible that some of the SGA children were originally just short genetically and not really growth retarded during intrauterine life. To avoid the possible influence of pubertal growth spurt already at $12 \mathrm{y}$, and because catch-up growth occurs mainly during the first years of life (32), we estimated catch-up growth by the age of $5 \mathrm{y}$. In previous reports, catch-up growth has usually been defined as an increase in height $>-2 \mathrm{SD}$ score or the 3rd percentile (32-34). For statistical purposes, we used a 2 SD score increase in height as the limit for good catch-up growth. Thirty-six percent of the SGA children passed this limit.

The timing of puberty was very similar in the SGA and AGA groups. This agrees with a Swedish study, in which the authors concluded that puberty is not delayed in children born SGA (32). Furthermore, concentrations of serum TC and LDL cholesterol may have a decreasing trend during puberty (35). Consequently, it is unlikely that the differences we detected in the serum lipid concentrations can be explained by differences in pubertal development because the pubertal development was similarly advanced in our SGA and control groups.

Previous data concerning the relationship between low birth weight or fetal growth retardation and serum lipids or lipoproteins in childhood are very limited. Donker et al. (14) reported that low birth weight was associated with elevated serum TG concentration in 7- to 11-y-old American children, whereas Antal et al. (15) found no association between birth weight and serum lipid concentrations in 14- to 16-y-olds born with low and normal birth weight. In these studies, the subjects were of varying gestational ages, including also preterm subjects. In addition, they represented different stages of pubertal development at the time of the study. Because of these aspects, the previously mentioned studies are not directly comparable to each other or to the present study. In a recent retrospective Finnish study of men born in 1924-1933 in Helsinki, the highest death rates caused by coronary heart disease were seen in boys who were thin at birth and whose weight caught up so that they had an average or above-average body mass index from the age of $7 \mathrm{y}$ onward (36). In the present study, we found no association between body mass index at 5 or $12 \mathrm{y}$ of age and serum lipid concentrations, nor did catch-up growth in weight increase the risk of high TC level in the SGA children. However, our results indicated that poor catch-up growth in height increased the risk of high TC level nearly 14-fold in the SGA children at the age of $12 \mathrm{y}$, compared with those SGA children who had good catch-up growth in height.

Hypercholesterolemia, as defined in our population, was found in 13 children (12\%) in the whole study population. Although this sample was selected, the prevalence of hypercholesterolemia was high. Mean TC concentration was 4.58 $\mathrm{mM}$ in the SGA group and $4.33 \mathrm{mM}$ in the AGA group, whereas LDL concentrations were $2.85 \mathrm{mM}$ and $2.62 \mathrm{mM}$, respectively. Between 1980 and 1992, mean TC levels have decreased from 4.88 to $4.47 \mathrm{mM}$ and LDL cholesterol levels from 3.06 to $2.85 \mathrm{mM}$ in Finnish children and young adults 
(37). Thus, the mean TC and LDL cholesterol concentrations of our study population were in accordance with the recent levels observed in the Cardiovascular Risk in Young Finns Study in 1992.

Not only neonatally increased morbidity and mortality, but also short stature in adulthood and increased prevalence of cardiovascular diseases later in life may be problems of children born SGA. The underlying mechanisms linking retarded fetal growth with cardiovascular diseases have not yet been recognized. It has been suggested that the endocrine axes are programmed by retarded intrauterine growth during critical phases of fetal development (11). In conclusion, to be born SGA has long-term consequences in later growth and may already influence the level of serum TC before the teens. SGA children with poor catch-up growth in height may be at the highest risk for hypercholesterolemia.

The authors thank Anneli Pere, M.D., for valuable advice on analyzing the growth data.

\section{REFERENCES}

1. Tracy RE, Newman WP, Wattigney WA, Srinivasan SR, Strong JP, Berenson GS 1995 Histologic features of atherosclerosis and hypertension from autopsies of young individuals in a defined geographic population: the Bogalusa heart study. Atherosclerosis 116:163-179

2. Berenson GS, Srinivasan SR, Bao W, Newman WP, Tracy RE, Wattigney WA 1998 Association between multiple cardiovascular risk factors and atherosclerosis in children and young adults. N Engl J Med 338:1650-1656

3. Sporik R, Johnstone JH, Cogswell JJ 1991 Longitudinal study of cholesterol values in 68 children from birth to 11 years of age. Arch Dis Child 66:134-137

4. Lauer RM, Lee J, Clarke WR 1988 Factors affecting the relationship between childhood and adult cholesterol levels: the Muscatine study. Pediatrics 82:309-318

5. Porkka KV, Viikari JS, Taimela S, Dahl M, Åkerblom HK 1994 Tracking and predictiveness of serum lipid and lipoprotein measurements in childhood: a 12-year follow-up. Am J Epidemiol 140:1096-1110

6. Barker DJP, Hales CN, Fall CHD, Osmond C, Phipps K, Clark PMS 1993 Type 2 (non-insulin-dependent) diabetes mellitus, hypertension and hyperlipidaemia (syndrome X): relation to reduced fetal growth. Diabetologia 36:62-67

7. Barker DJP, Fall CHD 1993 Fetal and infant origins of cardiovascular disease. Arch Dis Child 68:797-799

8. Barker DJP 1994 Outcome of low birth weight. Horm Res 42:223-230

9. Barker DJP 1997 Intrauterine programming of coronary heart disease and stroke. Acta Paediatr Suppl 423:178-182

10. Barker DJP, Osmond C, Simmonds SJ, Wield GA 1993 The relation of small head circumference and thinness at birth to death from cardiovascular disease in adult life. BMJ 306:422-426

11. Barker DJP, Gluckman PD, Godfrey KM, Harding JE, Owens JA, Robinson JS 1993 Fetal nutrition and cardiovascular disease in adult life. Lancet 341:938-941

12. Forsen T, Eriksson JG, Tuomilehto J, Teramo K, Osmond C, Barker DJP 1997 Mother's weight in pregnancy and coronary heart disease in a cohort of Finnish men: follow up study. BMJ 315:837-840

13. Barker DJP, Martyn CN, Osmond C, Hales CN, Fall CHD 1993 Growth in utero and serum cholesterol concentrations in adult life. BMJ 307:1524-1527
14. Donker G, Labarthe D, Harrist R, Selwyn B, Srinivasan S, Wattigney W, Berenson G 1997 Low birth weight and serum lipid concentrations at age 7-11 years in a biracial sample. Am J Epidemiol 145:398-407

15. Antal M, Agfalvi R, Nagy K, Szepvölgyi J, Banto E, Regöly-Merei A, Biro L, Biro GY 1998 Lipid status in adolescents born with low birth weight. Z Ernährungswiss 37(suppl 1):131-133

16. Ibanez L, Potau N, deZegher F 1999 Precocious pubarche, dyslipidemia, and low IGF binding protein-1 in girls: relation to reduced prenatal growth. Pediatr Res 46:320322

17. Albertsson-Wikland K, Boguszewski M, Karlberg J 1998 Children born small-forgestational age: postnatal growth and hormonal status. Horm Res 49:7-13

18. Karlberg J, Albertsson-Wikland K 1995 Growth in full-term small-for-gestational-age infants: from birth to final height. Pediatr Res 38:733-739

19. Luo Z-C, Albertsson-Wikland K, Karlberg J 1998 Length and body mass index at birth and target height influences on patterns of postnatal growth in children born small for gestational age. Pediatrics 102:e72

20. Leger J, Limoni C, Collin D, Czernichow P 1998 Prediction factors in the determination of final height in subjects born small for gestational age. Pediatr Res 43:808812

21. Salomaa V, Miettinen H, Kuulasmaa K, Niemelä M, Ketonen M, Vuorenmaa T, Lehto S, Palomäki P, Möhönen M, Immonen-Räihä P, Arstila M, Kaarsalo E, Mustaniemi H, Torppa J, Tuomilehto J, Puska P, Pyörälä K 1996 Decline of coronary heart disease mortality in Finland during 1983 to 1992: roles of incidence, recurrence and case-fatality. The FINMONICA MI register study. Circulation 94:3130-3137

22. Pihkala J, Hakala T, Voutilainen P, Raivio K 1989 New Finnish fetal growth charts [in Finnish]. Duodecim 105:1540-1546

23. Dubowitz LM, Dubowitz V, Goldberg C 1970 Clinical assessment of gestational age in the newborn infant. J Pediatr 77:1-10

24. Salo MK, Viikari J, Nuutinen M, Kaitila I, Sipilä I, Åkerblom H, Komulainen J, Siimes M, Simell O 1994 Diagnosis and treatment in hypercholesterolemia and other dyslipidemias in childhood [in Finnish]. Duodecim 110:1719-1723

25. Pere A, Perheentupa J, Peter M, Voutilainen R 1995 Follow up of growth and steroids in premature adrenarche. Eur J Pediatr 154:346-352

26. Martikainen MA 1988 Outcome of babies born to hypertensive mothers. PhD thesis, Kuopio University, Kuopio, Finland

27. Herrgård E 1993 Neurodevelopmental profile at the age of five years of children born preterm at $\leq 32$ weeks of gestation. PhD thesis, Kuopio University, Kuopio, Finland

28. Marshall WA, Tanner JM 1969 Variations in pattern of pubertal changes in girls. Arch Dis Child 44:291-294

29. Marshall WA, Tanner JM 1970 Variations in pattern of pubertal changes in boys. Arch Dis Child 45:13-16

30. Central Statistical Office of Finland 1989 Classification of socio-economic groups [in Finnish]. Hakapaino Press, Helsinki

31. Friedewald WT, Levy RJ, Fredrickson DS 1972 Estimation of the concentration of low-density-lipoprotein cholesterol in plasma without use of the preparative ultracentrifuge. Clin Chem 18:499-502

32. Albertsson-Wikland K, Wennergren G, Wennergren M, Vilbergsson G, Rosberg S 1993 Longitudinal follow-up of growth in children born small for gestational age. Acta Paediatr 82:438-443

33. Albertsson-Wikland K, Karlberg J 1994 Natural growth in children born small for gestational age with and without catch-up growth. Acta Paediatr Suppl 399:64-70

34. Hokken-Koelega ACS, De Ridder MAJ, Lemmen RJ, Den Hartog H, De Muinck Keizer-Schrama SMPF, Drop SLS 1995 Children born small for gestational age: do they catch up? Pediatr Res 38:267-271

35. Porkka KV, Viikari JS, Rönnemaa T, Marniemi J, Åkerblom HK 1994 Age and gender specific serum lipid and apolipoprotein fractiles of Finnish children and young adults. The Cardiovascular Risk in Young Finns Study. Acta Paediatr 83:838-848

36. Eriksson JG, Forsen T, Tuomilehto J, Winter PD, Osmond C, Barker DJP 1999 Catch-up growth in childhood and death from coronary heart disease: longitudinal study. BMJ 318:427-431

37. Porkka KV, Raitakari OT, Leino A, Laitinen S, Räsänen L, Rönnemaa T, Marniemi J, Lehtimäki T, Taimela S, Dahl M, Uhari M, Åkerblom HK, Viikari JSA 1997 Trends in serum lipid levels during 1980-1992 in children and young adults. The Cardiovascular Risk in Young Finns Study. Am J Epidemiol 146:64-77 